\title{
Tobacco cessation support among dentists: A cross-sectional survey in Saudi Arabia and Kuwait
}

\author{
Basais Alajmi', 2, Osoma Abu-Hommad 3, 4 , Ahmad Al-Sharrad², Najla Dar-Odeh ${ }^{3,4}$
}

\begin{abstract}
INTRODUCTION This study aims to explore the smoking prevalence among a sample of dentists working in two Gulf countries, and to assess the association between smoking habit and socioprofessional factors affecting their attitude towards tobacco cessation activities, including barriers that prevent them from practicing such activities.

METHODS This was a cross-sectional, online questionnaire-based, survey among dentists from Saudi Arabia and Kuwait, during summer 2016. The questionnaire consisted of questions on socio-professional characteristics, tobacco use and attitudes towards the adoption of tobacco cessation programs in dental practices. The questionnaire also enquired about the barriers to adoption of tobacco cessation. Descriptive statistics were used to describe demographic and smoking characteristics while cross tabulation with chi-square test was used to find out statistical significance of association between the groups $(\mathrm{P} \leq 0.05)$.

RESULTS A total number of 466 responses were included in statistical analysis with 286 males $(61.4 \%)$ and 180 females $(38.6 \%)$, age ranged from 23 to 79 years (mean=32.7 \pm 9.32$)$. Most of the sample ( $\mathrm{N}=437,93.8 \%)$ indicated that the dentist has a vital role in educating patients on the health hazards of smoking. A positive attitude toward adoption of tobacco cessation campaigns was associated with older, more experienced, medically compromised, non-smoker dentists. The most frequently cited barrier to tobacco cessation was lack of time $(39.2 \%)$.

conclusions Dentists who smoke are less likely to adopt smoking cessation campaigns in their clinics. More experienced dentists and those older than 40 years are more likely to engage in smoking cessation activities.
\end{abstract}

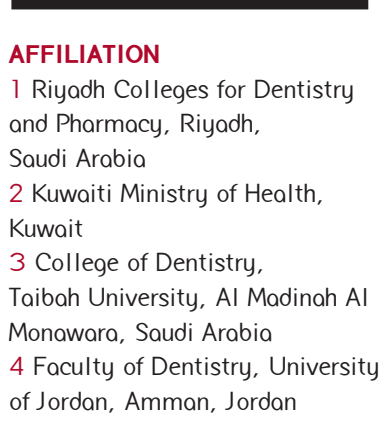

Received: 14 May 2017 Revised: 1 July 2017

Accepted: 10 July 2017

\section{INTRODUCTION}

Among health care professionals dentists have a fundamental obligation to fight tobacco use and to promote healthy oral conditions $^{1}$. The patient-dentist relationship is unique; the dentist has the opportunity to meet his/her patient over many visits, which provides the chance to initiate and reinforce tobacco cessation practices $^{2}$. It is estimated that about $50 \%$ of patients do get in contact with their dentist once a year ${ }^{3}$. Dentists are experienced and knowledgeable in diagnosing oral disease ${ }^{4}$, particularly the adverse oral health effects of tobacco smoking 5 , which on many occasions are present as potentially malignant or malignant lesions ${ }^{6,7}$.

Furthermore, dentists can adopt a strategy to convince and support their patients' efforts to quit smoking and maintain cessation. Dentists can educate vulnerable populations like children, adolescents and young females on the health hazards of smoking.8.

Dentists' willingness to assume a proactive role in tobacco cessation may be influenced by their socio-professional characteristics making it necessary to identify which dentists are ready to take on this important role. Socio-professional characteristics of dentists were found to influence prescribing practices $^{9}$, and their age, in particular, was found to affect their attitude towards tobacco cessation ${ }^{10}$. Another important aspect of tobacco cessation in the dental setting is the smoking status of dentists. Previous research found that smoking dentists are less likely to be engaged in tobacco cessation. In the last 15-20 years more studies have been conducted to address the role of dentists in preventing smoking and encouraging patients to quit $^{11}$. Studies that investigated this aspect of dental practice also 
aimed at understanding the barriers that may impede this vital role of dentists.

The aim of the present study was to explore the smoking prevalence among a sample of dentists from two Gulf countries, in a geographical area of the world known for the high prevalence of tobacco use and hence an urgent need to initiate tobacco cessation campaigns. The study also assessed the association between smoking habit and the socio-professional characteristics of dentists and their attitude towards tobacco cessation, including barriers that prevent them from conducting tobacco cessation activities.

\section{METHODS}

The study was a questionnaire-based study where an online questionnaire was prepared using Google forms ${ }^{\circledR}$ and a link was created. Questions were written in English, translated to Arabic and then translated back to English by another translator (for validity purposes). Translation to Arabic was modified until the back-to-English translation matched the original questions.

It was first distributed to 10 dentists, and was re-sent to the same participants after one week. Different responses by the same participant were checked for clarity/aim, then the wording was changed when necessary until there were no differences in the responses. The link to the questionnaire and an invitation to participate were distributed by email to dentists registered with the Saudi Commission for Health Specialties as well as the Kuwaiti Dental Association.

Questions collected data on certain socio-professional factors including: gender, age, nationality, marital status, having children, date of graduation, country of graduation, specialty (if present), and history of medical problems that required long-term use of medications. There was a section pertaining to tobacco smoking that collected data on the dentists' own tobacco use and attitude towards: patient education on the health hazards of tobacco, routine enquiry of patients regarding their tobacco use habits, offering quitting advice to smoker patients, willingness to undertake a tobacco cessation activity in the clinic, and routine screening for signs and symptoms of oral cancer. Inclusion criteria included being a dentist registered with Saudi Commission for Health Specialties or Kuwaiti Dental Association.

Sample size determination was carried out using Epi Info software (Center for Disease Control, CDC, USA). The results of sample size determination were based on the following: total number of dentists working in Saudi Arabia ( $\mathrm{N}=13,502)$, and total number of dentists working in Kuwait $(\mathrm{N}=4,346)$ yielding a population size of 17,848 , expected frequency of tobacco smoking among dentists of $25 \%$, confidence limit of $5 \%$, and one cluster. A sample size of 466 produced a power of the study between $97 \%$ and $99 \%$.

Participants were invited and responses were accepted during the time interval 11 April to 10 September 2016.

Ethical approval was obtained from the Research Center of the Riyadh Colleges of Dentistry and Pharmacy, Riyadh; registration number (FPGRP/43531009/76).

\section{Statistical analysis}

Responses were entered and analyzed using the IBM SPSS software version 21.0. Descriptives and frequencies were obtained, and data were cross-tabulated to determine the significance of association between the dentists' smoking habits and socio-professional factors, significance of association between dentists' smoking habits and attitudes toward smoker patients' education, examination and awareness, and lastly the significance of association between willingness to undertake a tobacco cessation campaign in the clinic and socio-professional factors. For statistical analysis, the groups were categorized as follows: Age ( $\leq 40$ years, $>40$ years), nationality (Gulf, Arab, and non-Arab), date of graduation (before 2002, 2002-2015), country of graduation (Gulf, other Arab countries, Western countries, others). Chi-square test was used, and significance was set at $\mathrm{P} \leq 0.05$.

\section{RESULTS}

Total number of respondents was 479. Among the total sample of 479 , a number of 13 responses were excluded because they were either incomplete or were received from other allied dental fields like dental hygienists and dental technicians. This reduced the final sample of the study to 466 subjects giving a response rate of $2.6 \%$. Age ranged from 23 to 79 years with mean age of $32.7 \pm 9.32$ years. Females were $180(38.6 \%)$ and males were 286 (61.4\%). Socio-professional characteristics and their statistical significance of association with smoking status and the willingness to conduct tobacco cessation activities are shown in Table 1 . Not all responses added to 466 because some participants chose not to answer to all questions.

Date of graduation ranged from 1950-2015, with the median being: 2006 or an average experience of $11.74 \pm 10.57$ years.

Most of the subjects $(n=433)$ reported 23 countries of graduation for their bachelor's degree and these were divided into three categories for the purpose of statistical analysis. The following socio-professional characteristics were statistically significantly associated with smokers: male gender $(\mathrm{P}=0.000)$, age $\leq 40$ years $(\mathrm{P}=0.005)$, newly graduated $(\mathrm{P}=0.006)$, and an Arabic country of graduation ( $\mathrm{P}=0.002)$, as shown in Table1. The following socio-professional characteristics were statistically 


\section{Research paper}

Table 1. Socio-professional factors of study sample and their statistical significance of association with smoking status and the willingness to undertake tobacco cessation activities (n-466) in Saudi Arabia and Kuwait, 2016

\begin{tabular}{|c|c|c|c|c|c|c|}
\hline \multirow[t]{2}{*}{ Characteristics } & \multicolumn{2}{|c|}{$\begin{array}{l}\text { Smokingstatus } \\
(\mathrm{n}, \%)\end{array}$} & \multirow[t]{2}{*}{ Pvalue } & \multicolumn{2}{|c|}{$\begin{array}{l}\text { Willingness to undertake tobacco } \\
\text { cessation campaign (n,\%) }\end{array}$} & \multirow[t]{2}{*}{ Pvalue } \\
\hline & $\begin{array}{c}\text { Yes } \\
(126,27 \%)\end{array}$ & $\begin{array}{c}\text { No } \\
(310,73 \%)\end{array}$ & & $\begin{array}{c}\text { Yes } \\
(336,72.7 \%)\end{array}$ & $\begin{array}{c}\text { No } \\
(126,27.3 \%)\end{array}$ & \\
\hline $\begin{array}{l}\text { Gender } \\
\text { Males }(n=286) \\
\text { Females }(n=180)\end{array}$ & $\begin{array}{r}106(37.1 \%) \\
20(11.1 \%)\end{array}$ & $\begin{array}{l}180(62.9 \%) \\
160(88.9 \%)\end{array}$ & $0.000^{*}$ & $\begin{array}{l}204(71.3 \%) \\
132(73.3 \%)\end{array}$ & $\begin{array}{l}79(27.6 \%) \\
47(26.1 \%)\end{array}$ & 0.791 \\
\hline $\begin{array}{l}\text { Age } \\
\leq 40 \text { years }(n=394) \\
>40 \text { years }(n=68)\end{array}$ & $\begin{array}{r}116(29.4 \%) \\
9(13.2 \%)\end{array}$ & $\begin{array}{r}278(70.6 \%) \\
59(86.8 \%)\end{array}$ & $0.005^{*}$ & $\begin{array}{r}278(70.6 \%) \\
55(80.9 \%)\end{array}$ & $\begin{array}{r}114(28.9 \%) \\
11(16.2 \%)\end{array}$ & $0.016^{*}$ \\
\hline $\begin{array}{l}\text { Nationality } \\
\text { Gulf }(n=391) \\
\text { Arab }(n=48) \\
\text { Non-Arab }(n=12)\end{array}$ & $\begin{array}{r}108(27.7 \%) \\
12(24.5 \%) \\
2(16.7 \%)\end{array}$ & $\begin{array}{r}282(72.3 \%) \\
37(75.5 \%) \\
10(83.3 \%)\end{array}$ & 0.638 & $\begin{array}{r}278(71.3 \%) \\
35(71.4 \%) \\
11(91.7 \%)\end{array}$ & $\begin{array}{r}108(27.7 \%) \\
14(28.6 \%) \\
1(8.3 \%)\end{array}$ & 0.569 \\
\hline $\begin{array}{l}\text { Marital status } \\
\text { Married }(n=296) \\
\text { Single }(n=151) \\
\text { Divorced }(n=18)\end{array}$ & $\begin{array}{c}85(28.7 \%) \\
35(23.2 \%) \\
6(33.3 \%)\end{array}$ & $\begin{array}{r}211(71.3 \%) \\
116(76.8 \%) \\
12(66.7 \%)\end{array}$ & 0.514 & $\begin{array}{r}214(72.3 \%) \\
108(71.5 \%) \\
13(72.2 \%)\end{array}$ & $\begin{array}{r}80(27 \%) \\
41(27.2 \%) \\
5(27.8 \%)\end{array}$ & 0.984 \\
\hline $\begin{array}{l}\text { Have children } \\
\text { Yes }(n=255) \\
\text { No }(n=211)\end{array}$ & $\begin{array}{l}73(28.6 \%) \\
53(25.1 \%)\end{array}$ & $\begin{array}{l}182(71.4 \%) \\
158(74.9 \%)\end{array}$ & 0.396 & $\begin{array}{r}184(72.2 \%) \\
152(72 \%)\end{array}$ & $\begin{array}{r}69(27.1 \%) \\
57(27 \%)\end{array}$ & 0.982 \\
\hline $\begin{array}{l}\text { Date of Grad } \\
\text { Experienced }(n=85) \\
\text { Newly graduate }(n=378)\end{array}$ & $\begin{array}{r}13(15.3 \%) \\
113(29.9 \%)\end{array}$ & $\begin{array}{r}72(84.7 \%) \\
265(70.1 \%)\end{array}$ & $0.006^{*}$ & $\begin{array}{r}69(81.2 \%) \\
264(69.8 \%)\end{array}$ & $\begin{array}{r}14(16.5 \%) \\
112(29.6 \%)\end{array}$ & $0.016^{*}$ \\
\hline $\begin{array}{l}\text { Country of Grad } \\
\text { Gulf }(n=264) \\
\text { Arab }(n=124) \\
\text { Western }(n=30) \\
\text { Other }(n=30)\end{array}$ & $\begin{array}{r}63(23.9 \%) \\
49(39.5 \%) \\
7(18.9 \%) \\
5(14.3 \%)\end{array}$ & $\begin{array}{r}201(76.1 \%) \\
75(60.5 \%) \\
30(81.1 \%) \\
30(85.7 \%)\end{array}$ & $0.002^{*}$ & $\begin{array}{r}189(71.6 \%) \\
83(66.9 \%) \\
30(81.1 \%) \\
28(80 \%)\end{array}$ & $\begin{array}{r}72(27.3 \%) \\
40(32.3 \%) \\
7(18.9 \%) \\
7(20 \%)\end{array}$ & 0.573 \\
\hline $\begin{array}{l}\text { Specialty } \\
\text { Yes }(n=182) \\
\text { No }(n=284)\end{array}$ & $\begin{array}{l}49(26.9 \%) \\
77(27.1 \%)\end{array}$ & $\begin{array}{l}133(73.1 \%) \\
207(72.9 \%)\end{array}$ & 0.964 & $\begin{array}{l}128(70.3 \%) \\
208(73.2 \%)\end{array}$ & $\begin{array}{l}53(29.1 \%) \\
73(25.7 \%)\end{array}$ & 0.625 \\
\hline $\begin{array}{l}\text { Illnesses } \\
\text { Yes }(n=54) \\
\text { No }(n=406)\end{array}$ & $\begin{array}{r}12(22.2 \%) \\
112(27.6 \%)\end{array}$ & $\begin{array}{r}42(77.8 \%) \\
294(72.4 \%)\end{array}$ & 0.665 & $\begin{array}{r}41(75.9 \%) \\
293(72.2 \%)\end{array}$ & $\begin{array}{r}13(24.1 \%) \\
112(27.6 \%)\end{array}$ & $0.000^{*}$ \\
\hline
\end{tabular}

* Statistically significant

Percentages are calculated according to the number of responses to each question.

Table 2. Statistical significance of association between smoking status of dentists and their tobacco cessation attitudes (n=466) in Saudi Arabia and Kuwait, 2016

\begin{tabular}{|c|c|c|c|}
\hline \multirow{2}{*}{$\begin{array}{l}\text { Tobaccocessation } \\
\text { attitudes }\end{array}$} & \multicolumn{2}{|c|}{ Smoking status n (\%) } & \multirow[t]{2}{*}{ Pvalue } \\
\hline & $\begin{array}{c}\text { Yes } \\
(\mathrm{N}=126,27 \%)\end{array}$ & $(\mathrm{N}-310,73 \%)$ & \\
\hline $\begin{array}{l}\text { Patient education } \\
\text { Yes }(n=437) \\
\text { No }(n=25)\end{array}$ & $\begin{array}{r}110(25.2 \%) \\
14(56 \%)\end{array}$ & $\begin{array}{r}327(74.8 \%) \\
11(44 \%)\end{array}$ & 0.002 \\
\hline $\begin{array}{l}\text { Routine asking of tobacco use } \\
\text { Yes }(n=315) \\
\text { No }(n=147)\end{array}$ & $\begin{array}{r}78(24.8 \%) \\
47(32 \%)\end{array}$ & $\begin{array}{r}237(75.2 \%) \\
100(68 \%)\end{array}$ & 0.266 \\
\hline $\begin{array}{l}\text { Give quit advice to smokers } \\
\text { Yes }(n=357) \\
\text { No }(n=105)\end{array}$ & $\begin{array}{l}77(21.6 \%) \\
48(45.7 \%)\end{array}$ & $\begin{array}{r}280(78.4 \%) \\
57(54.3 \%)\end{array}$ & 0.000 \\
\hline $\begin{array}{l}\text { Willingness to conduct a cessation compaign } \\
\text { Yes }(n=336) \\
\text { No }(n=126)\end{array}$ & $\begin{array}{l}73(21.7 \%) \\
52(41.3 \%)\end{array}$ & $\begin{array}{r}263(78.3 \%) \\
74(58.7 \%)\end{array}$ & 0.000 \\
\hline $\begin{array}{l}\text { Routine screen for oral cancer } \\
\text { Yes }(n=378) \\
\text { No }(n=82)\end{array}$ & $\begin{array}{r}104(27.5 \%) \\
20(24.4 \%)\end{array}$ & $\begin{array}{r}274(72.5 \%) \\
62(75.6 \%)\end{array}$ & 0.796 \\
\hline
\end{tabular}


Table 3: Reasons considered by dentists as barriers for conducting tobacco cessation campaigns in their clinics (n=181/466) in Saudi Arabia and Kuwait, 2016

$\begin{array}{ll}\text { Reason } & \text { Number (\%) } \\ \text { I lack time } & 71(39.2) \\ \text { I am afraid the patients will not be happy to } & 51(28.3) \\ \text { receive this service } & 23(12.8) \\ \text { I lack education on the topic } & 14(7.7) \\ \text { I believe dentists don't have a role in tobacco } & 11(6.1) \\ \text { cessation } & \\ \text { I am not convinced of the effectiveness of such } \\ \text { campaigns }\end{array}$

significantly associated with willingness to undertake tobacco cessation campaign: age $>40$ years $(\mathrm{P}=0.016)$, experienced dentists $(\mathrm{P}=0.016)$, and dentists with chronic illness $(\mathrm{P}=0.000)$ as shown in Table1.

A number of $126(27 \%)$ indicated that they use one or more tobacco products. Tobacco use was in the form of one or more of the following methods: cigarettes, waterpipe, cigars and electronic cigarettes. However, 89 (19.1\%) considered themselves light or regular smokers. The rest of the tobacco users considered themselves as non-smokers or indicated they were just passing time by smoking.

Subjects indicated age of onset of smoking ranging from: $12-37$ years, with mean age: $20.41 \pm 4.37$ years. A total of 437 (93.8\%) indicated that the dentist has a vital role in educating their patients on the dangers of smoking. Twenty five (5.4\%) believed otherwise and 4 subjects did not respond. Other attitudes towards tobacco smoking are shown in Table 2, including routine enquiry on a patient's smoking habits, advising smoker patients to quit, and routine oral screening for signs and symptoms of oral cancer. A non-smoker status was statistically significantly associated with the following tobacco cessation attitudes: patient education ( $\mathrm{P}=0.002)$, giving quit advice to smokers $(\mathrm{P}=0.000)$, and willingness to conduct a tobacco cessation campaign $(\mathrm{P}=0.000)$, as shown in Table 2 .

A total of 129 dentists responded to the question on barriers to initiating tobacco cessation activities, and some of them cited more than one barrier. Barriers are given in Table 3.

\section{DISCUSSION}

This study attempted to find if there is any association between important socio-professional characteristics of dentists and their tobacco use habit. It also attempted to investigate whether these socio-professional characteristics and the dentist's tobacco use habit can influence their attitude towards providing professional tobacco cessation activities. The main finding was that smoker dentists show no willingness to engage in tobacco cessation activities, including patient education, giving patients quit advice, or conducting tobacco cessation campaigns. This indicates how important it is to design specific tobacco cessation campaigns directed to healthcare professionals like dentists to help them quit smoking.

The concept of inter-professional practice in providing patient healthcare is gaining popularity, and has become widely promoted to encourage collaboration of all healthcare professionals with the goal of optimizing health services provided to patients. No single profession can provide optimum patient care when acting alone. Dentists are no exception; they are also part of the healthcare team and they have a responsibility to integrate their professional skills with those of colleagues to provide patients with a comprehensive and satisfactory treatment plan ${ }^{12}$. It is now time for dentists to extend their care to their patients beyond their traditional role to address a patient's need for an overall well-being and a quality of life. Among these responsibilities tobacco cessation activities stand out as an important aspect of oral healthcare. Furthermore, healthcare providers including dentists have a responsibility to stay informed about new smoking trends that may affect patients, such as waterpipe, e-cigarettes and other potential gateways to nicotine addiction ${ }^{13}$.

Smokers constituted $27 \%$ of the study sample. Recent studies reported almost the same prevalence of smoking among a sample of physicians and dentists in Iraq and Saudi Arabia ${ }^{14,}$ ${ }^{15}$, but higher than dentists in Yemen where $20 \%$ of the study sample were smokers $^{16}$. In the current study, a smoking dentist was more likely to be: male, age less than 40 years, and a professional experience of less than 15 years. Smoking worldwide has a higher prevalence amongst men, and this finding is also encountered in this sample of dentists. Females in developing countries are reported to have a much lower prevalence of smoking (3.1\%) compared to male smoking prevalence $(32 \%)^{17}$. However, care should be taken when investigating epidemiological aspects of smoking in relation to gender due to denial behavior of some females, in conservative societies, who withhold information regarding their smoking in reaction to societal disapproval ${ }^{18}$. Furthermore, new trends of tobacco use are attracting the female populations, particularly in developing countries ${ }^{19}{ }^{20}$. Smokers in this sample utilized methods of tobacco use that included: cigarettes, waterpipe, cigars and electronic cigarettes. However, a denial attitude prevailed with most of the smokers considering themselves as 
light smokers or just passing time by smoking. This behavior seems to be related to what is called "social smoking", a behavior that is associated with denial of tobacco addiction and self-categorization as non-smokers ${ }^{21}$. On the other hand, this may represent a feeling of guilt particularly if that is in conflict with their perceived role in combating health risk behavior. Furthermore, some of the smokers use e-cigarettes and waterpipe. Both tobacco use methods are relatively new and popular trends in smoking, which are being promoted as a safer alternative to cigarettes ${ }^{22,23}$. Smoking was also found to be significantly associated with age younger than 40 years and graduates of years 2002-2015, or newly graduates.

The relationship between these two socio-professional factors is not unexpected. The finding that younger dentists have a higher smoking prevalence than their older colleagues may be explained by the appearance of new trends in smoking such as waterpipe and electronic cigarettes, as these generally attract the younger generations ${ }^{24,25}$. Graduates of Gulf and Arab countries have shown a statistically significant higher smoking prevalence probably because of the weak implementation of smoke-free policies that are encountered in universities of developing countries. The rest of the socioprofessional factors had no association with tobacco use including: nationality, being a specialist, marital status and having children. This probably emphasizes that maturity resulting from age plays a more important role than other social and professional factors.

Willingness to conduct tobacco cessation activities in the clinic was found to be significantly associated with dentists older than 40 years. The age association was reported by another study conducted among dentists in Hong Kong ${ }^{10}$, however another study conducted in the UK found that young dentists are more likely to give smoking cessation support ${ }^{26}$. In general, older age for dentists means more professional maturation as well as financial and professional stability. Older dentists are more likely to be exposed to a higher number of patients with oral diseases that are directly related to smoking such as periodontal disease, and potentially malignant or malignant lesions. They are generally more capable of managing their time to address preventive as well as therapeutic care. Older dentists are also expected to have stable families that need less attention and time. In Western countries like the UK, more emphasis is given to prevention in dental practice with a more favorable attitude towards tobacco cessation and corresponding programs within undergraduate and postgraduate dental curricula. This may explain the positive attitude that young dentists in the UK have towards a proactive role in tobacco cessation compared to the present sample of dentists. A highly significant association was noticed between positive tobacco cessation attitude and the presence of a positive medical history $(\mathrm{P}=.000)$. Older dentists in this study were found to have a better attitude, and since many chronic disease are associated with older age, this fact may explain the aforementioned finding. Another explanation could be that healthcare professionals who have systemic illness are generally aware of health risk behavior and are more willing to use their experience and time to combat such behavior.

In recent years there has been a noticeable growth in the number and quality of studies on the effectiveness of tobacco cessation interventions in dental clinics. Further, several countries have developed ways to encourage the involvement of dentists in tobacco cessation programs ${ }^{27,28}$.

Unfortunately, this professional role may be jeopardized when dentists are smokers. Dentists who smoke show a less positive attitude towards smoking cessation campaigns ${ }^{29}$, which is reflected in the association between a dentist's own smoking habit and desire to help patients to quit smoking ${ }^{6}$. This association is confirmed in this study; there was a significant association between the dentists' smoking status and their willingness to educate patients on the health hazards of tobacco use. There was a highly significant association between smoking status and giving quit-smoking advice to patients and willingness to conduct a tobacco cessation campaign. However, this is in contradiction with other studies ${ }^{30,31}$. Most smokers and non-smokers claim that they screen their patients for oral cancer, which confirms that this sample of dentists are generally aware of the health hazards of tobacco particularly sinister oral health hazards. Early screening for oral cancer is a prominent aspect in dental care that improves prognosis. It is mandatory for all patients attending dental treatment or a simple check-up to be screened for oral cancer, regardless of their tobacco use habits as many cases of oral cancer arise in non-smokers ${ }^{4}$. Smokers in this study were as likely as non-smokers to ask their patients about smoking habits. This may be explained by the fact that dentists are required to take and document a patient's medical history in their clinical records including smoking history.

Dentists were also asked about the barriers they perceive as important against tobacco cessation. The most frequently cited barrier was "lack of time" followed by "fear of patient dissatisfaction" and "lack of the necessary education on this issue". "Lack of time" was also a major barrier in other studies $^{32}$. Dental treatment is generally based on operative interventions that aim to address problems in oral function 
and esthetics taking into consideration the patient's medical history. Further, dentists are usually required to review the patient's medical history prior to dental treatment, and are expected to document all materials and medications given to patients in their clinical records ${ }^{33}$. This is challenging to dentists who have a limited time to treat a large number of patients, many as emergency situations that need urgent attention ${ }^{34}$. This inherent characteristic of the dental profession should not be overlooked when expecting dentists to be involved also with tobacco cessation. Although "lack of time" may seem a reasonable barrier for dentists who work in private practices, dentists working in the public sector can be encouraged to conduct tobacco cessation services as part of the national health scheme. This should overcome barriers such as "lack of time", and "lack of education". It has been recommended that clinicians who lack time to conduct preventive services could involve others they supervise, provided that they set the agenda and provide the necessary resources to achieve the task ${ }^{35}$. Some participants cited "patient dissatisfaction" as a barrier. Contrary to the beliefs of many dentists, it was found that patients considered that involvement of dentists in tobacco cessation efforts is a sign of quality ${ }^{36}$, with a resultant patient satisfaction. It should be emphasized though that unlike other countries where dental treatment is not included in health insurance, nationals of Kuwait and Saudi Arabia enjoy free dental services provided by the respective Ministries of Health. This provides a great opportunity for tobacco cessation services to smokers through specialized clinics that are established under the umbrella of the Ministry of Health and run by various healthcare professionals including dentists. Efforts of the Ministries can be supported by the academic institutions that are now widely established in the Arab peninsula. Colleges of dentistry are now established in almost all major cities in Saudi Arabia, attracting many students of both sexes, and this is reflected in the growing number of dental graduates ${ }^{37}$.

\section{Study limitations}

The sample size is considered to be relatively low with only $2.6 \%$ of the total dental workforce in Saudi Arabia and Kuwait participating in this study, however, sample size calculation was done and it was statistically sound. Data reported in this study are based on self-perceptions of participants that may involve withholdment of information. However, participation was voluntary and anonymous contributing to the reliability of data collected. This study has important implications for tobacco cessation efforts that are very much needed in this geographical area of the world where a high prevalence of smoking is reported. Furthermore, it provides essential data for policy makers to encourage dentists to be involved in the combat against prevalent health risk behavior such as smoking. The results of this study should draw the attention of dentists, who work in similar cultures, to the importance of this issue.

In conclusion, the availability of dentists, and the affordability of dental health care for the Saudi and Kuwaiti nationals are just two important factors that need to be supplemented by a clear and decisive plan from the Ministries of Health to establish well-organized tobacco cessation campaigns where dentists can contribute in an efficient and productive way.

\section{CONCLUSIONS}

This study shows that one in four dentists in Kuwait and Saudi Arabia is a smoker. Dentists show a favorable attitude toward initiating tobacco cessation activities, particularly when they are non-smokers and older than 40 years. Efforts should be organized on the national governmental level to address the obvious deficiency in tobacco cessation programs.

\section{REFERENCES}

1. Shaheen S, Reddy S, Doshi D, Reddy P, Kulkarni S: Knowledge, Attitude and Practice Regarding Tobacco Cessation Among Indian Dentists. Oral Health Prev Dent 2015, 13:427-434. doi: 10.3290/j.ohpd.a33924.

2. Albert DA, Severson H, Gordon J, Ward A, Andrews J, Sadowsky D: Tobacco attitudes, practices, and behaviors: a survey of dentists participating in managed care. Nicotine Tob Res 2005, 7 Suppl 1:S9-18.

doi: 10.1080/14622200500078014

3. Martin LM, Bouquot JE, Wingo PA, Heath CW, Jr.: Cancer prevention in the dental practice: oral cancer screening and tobacco cessation advice. J Public Health Dent 1996, 56:336-340. doi: 10.1111/j.1752-7325.1996.tb02461.x.

4. Dar-Odeh N, Abu-Hammad O: Tongue cancer subgroup. Br Dent J 2013, 215:154.

doi: 10.1038/sj.bdj.2013.796.

5. Albert D, Ward A, Ahluwalia K, Sadowsky D: Addressing tobacco in managed care: a survey of dentists' knowledge, attitudes, and behaviors. Am J Public Health 2002, 92:997-1001. doi: 10.2105/ajph.92.6.997.

6. Smith DR, Leggat PA: Tobacco smoking prevalence among a crosssection of dentists in Queensland, Australia. Kurume Med J 2005, 52:147-151.

7. Al-Kayyal M. A-HN: Dental Records and what they can Reveal about Tobacco Use Intervention Practices. Tob Prev Cessation 2017, 3:1-7. doi: $10.18332 /$ tpc/67969.

8. Shaik SS, Doshi D, Bandari SR, Madupu PR, Kulkarni S: Tobacco Use Cessation and Prevention - A Review. J Clin Diagn Res 2016, 10:ZE13-17.

doi: 10.7860/JCDR/2016/19321.7803 
9. Al-Shayyab MH, Abu-Hammad OA, Al-Omiri MK, Dar-Odeh NS: Antifungal prescribing pattern and attitude towards the treatment of oral candidiasis among dentists in Jordan. Int Dent J 2015, 65:216-226. doi: 10.1111/idj.12173.

10. Li KW, Chao DV: Current practices, attitudes, and perceived barriers for treating smokers by Hong Kong dentists. Hong Kong Med J 2014, 20:94-101. doi : 10.12809/hkmj134027

11. Omana-Cepeda C, Jane-Salas E, Estrugo-Devesa A, ChimenosKustner E, Lopez-Lopez J: Effectiveness of dentist's intervention in smoking cessation: A review. J Clin Exp Dent 2016, 8:e78-83. doi: $10.4317 /$ jced.52693

12. Valachovic RW: Integrating oral and overall health care--on the road to interprofessional education and practice: building a foundation for interprofessional education and practice. J Calif Dent Assoc 2014, 42:25-27.

13. Noonan D, Kulbok PA: New tobacco trends: waterpipe (hookah) smoking and implications for healthcare providers. J Am Acad Nurse Pract 2009, 21:258-260. doi: 10.1111/j.1745-7599.2009.00402.x.

14. Abdulateef DS, Ali AJ, Abdulateef DS, Mohesh MI: Smoking Knowledge, Attitude, and Practices Among Health Care Professionals from Sulaymaniyah City/Iraq. Tob Use Insights 2016, 9:1-6. doi: 10.4137/TUI.S38171.

15. Dar-Odeh N, Alnazzawi A, Shoqair N, Al-Shayyab MH, AbuHammad O: Waterpipe Tobacco Smoking Among Dental Practitioners: Prevalence and Health Perceptions. Tob Use Insights 2016, 9:29-33. doi: $10.4137 /$ TUI.S40568

16. Al-Maweri SA, Al-Soneidar WA, AlMaqtari A, Hunaish A, Al-Sufyani G, Halboub E: Tobacco Cessation Counseling: Attitudes and Practices among Yemeni Dental Professionals. J Cancer Educ 2017. doi : 10.1007/s13187-017-1212-9

17. Hagen EH, Garfield MJ, Sullivan RJ: The low prevalence of female smoking in the developing world: gender inequality or maternal adaptations for fetal protection? Evol Med Public Health 2016, 2016:195-211. doi: 10.1093/emph/eow013

18. Islam SM, Johnson CA: Correlates of smoking behavior among Muslim Arab-American adolescents. Ethn Health 2003, 8:319-337.

19. Dar-Odeh NS, Abu-Hammad OA: The changing trends in tobacco smoking for young Arab women; narghile, an old habit with a liberal attitude. Harm Reduct J 2011, 8:24.

doi : 10.1186/1477-7517-8-24

20. Dar-Odeh N.; Abu-Hammad O, Al-Abdalla, M.; Shakhatreh, F.; Al-Abedalla, K.; Khdairi, N.; Prime, S.: Narghile Smoking among Jordanian Educated Working Women: Attitudes and Beliefs. Br J Med Med Res 2013, 3:8.

21. Schane RE, Glantz SA, Ling PM: Social smoking implications for public health, clinical practice, and intervention research. Am J Prev Med 2009, 37:124-131.

doi: 10.1016/j.amepre.2009.03.020.

22. Hess CA, Olmedo P, Navas-Acien A, Goessler W, Cohen JE, Rule
AM: E-cigarettes as a source of toxic and potentially carcinogenic metals. Environ Res 2017, 152:221-225.

doi: 10.1016/j.envres.2016.09.026.

23. Dar-Odeh NS, Abu-Hammad OA: Narghile smoking and its adverse health consequences: a literature review. Br Dent J 2009, 206:571573. doi: $10.1038 /$ sj.bdj.2009.475.

24. McCarthy M: E-cigarettes are major threat to young people's health, says US surgeon general. BMJ 2016, 355:16652. doi: 10.1136/bmj.i6652

25. Soule EK, Lipato T, Eissenberg T: Waterpipe tobacco smoking: A new smoking epidemic among the young? Curr Pulmonol Rep 2015, 4:163-172. doi: 10.1007/s13665-015-0124-6.

26. Yusuf H, Tsakos G, Ntouva A, Murphy M, Porter J, Newton T, Watt RG: Differences by age and sex in general dental practitioners' knowledge, attitudes and behaviours in delivering prevention. $\mathrm{Br}$ Dent J 2015, 219:E7. doi: 10.1038/sj.bdj.2015.711.

27. Wilson M, Karki AJ, Gould A: Evaluation of the Stop Smoking Wales NHS Dental Practice Incentive Scheme. Br Dent J 2016, 221:731735 . doi:10.1038/sj.bdj.2016.916

28. Gallus S, Lugo A, Garattini S, Pacifici R, Mastrobattista L, Marzo G, Paglia L: General Practitioners and Dentists: A Call for Action Against Tobacco. Nicotine Tob Res 2016, 18:2202-2208. doi:10.1093/ntr/ntw162

29. Park YD, Patton LL, Kim JH, Kim HY: Smoking prevalence and attitude toward anti-smoking activities among Korean dentists. Int Dent J 2010, 60:383-38

30. Ford P, Tran P, Keen B, Gartner C: Survey of Australian oral health practitioners and their smoking cessation practices. Aust Dent J 2015, 60:43-51; quiz 128.

doi: 10.1111/adj.12270.

31. Uti OG, Sofola OO: Smoking cessation counseling in dentistry: attitudes of Nigerian dentists and dental students. J Dent Educ 2011, 75:406-412. doi: 10.4314/ndj.v15i2.42111.

32. Bhat N, Jyothirmai-Reddy J, Gohil M, Khatri M, Ladha M, Sharma M: Attitudes, Practices and Perceived Barriers in Smoking Cessation among Dentists of Udaipur City, Rajasthan, India. Addict Health 2014, 6:73-80.

33. Dar-Odeh NS, Abu-Hammad OA, Khraisat AS, El Maaytah MA, Shehabi A: An analysis of therapeutic, adult antibiotic prescriptions issued by dental practitioners in Jordan. Chemotherapy 2008, 54:17-22. doi.org/10.1159/000112313

34. Renshaw J: Dentist suicides. Br Dent J 2013, 215:593-594.

35. Kottke TE, Brekke ML, Solberg LI: Making «time» for preventive services. Mayo Clin Proc 1993, 68:785-791.

36. Kottke TE, Solberg LI, Brekke ML, Cabrera A, Marquez M: Will patient satisfaction set the preventive services implementation agenda? Am J Prev Med 1997, 13:309-316.

37. Al-Dlaigan YH, Albarakati SF, Al-Habeeb F, Al-Hulaily M: Career 


\section{Research paper}

characteristics and postgraduate education of female dentist graduates of the College of Dentistry at King Saud University, Saudi Arabia. Saudi Dent J 2012, 24:29-34.

doi: $10.1016 /$ j.sdentj.2011.10.005

CONFLICT OF INTERESTS

The authors have completed and submitted the ICME Form for Disclosure of Potential Conflicts of Interest and none were reported.

\section{FUNDING}

There was no source of funding for this research.

PROVENANCE AND PEER REVIEW

Not commissioned:

externally peer reviewed 